\title{
Adaptation of Diabetes-Specific Quality-of-Life Scale for patients with type 1 diabetes
}

Natalia Soledad Sahi ${ }^{1}$, Marcos Cupani ${ }^{2 *}$, Franco Daniel Cortez ${ }^{3}$ y Graciela Beatriz Rubin ${ }^{4}$

${ }^{1}$ Service of Diabetes, Clínica Privada Vélez Sarsfield, Faculty of Medical Sciences; 2 IIPsi - Instituto de Investigaciones Psicológicas (CONICET), Faculty of Psychology; ${ }^{3}$ Faculty of Psychology; ${ }^{4}$ Service of Diabetes and Nutrition, Obesity Area, Hospital Privado, Faculty of Medical Sciences. National University of Córdoba, Córdoba, Argentina

\section{ABSTRACT}

The diabetes-specific quality-of-life scale (DSQOLS) addresses accurately the differences between various forms of therapy in diabetes mellitus (DM) 1 and investigates the level of patient satisfaction with their current treatment in relation to their individual goals. The aim of this work is to adapt the DSQOLS to the population from Argentine. The 64-item questionnaire was administered online. The 223 people took part voluntarily (75.3\% were female), ranging between 18 and 85 years of age, giving their informed consent. A confirmatory factor analysis was performed to evaluate the internal structure of the questionnaire. Indexes of Cronbach's alpha were also obtained, and the scales scores were compared in relation to gender, use of insulin pump, physical activity, and participation in support groups. The results showed that the model fits properly to the data. The reliability of the scales was satisfac-

\section{RESUMEN}

EI DSQOLS (Diabetes Especific Quality of Life Scale) aborda con precisión las diferencias entre diversas formas de terapia en diabetes mellitus tipo 1 (DM1) e investiga el nivel de satisfacción de los pacientes con su tratamiento actual en relación con sus objetivos individuales. El objetivo de este trabajo es adaptar la escala DSQOLS a la población argentina. Los 64 ítems del instrumento fueron administrados en forma online. Participaron en forma voluntaria 223 personas (75.3\% fueron mujeres) de 18 a 85 años, que dieron su consentimiento informado. Para evaluar la estructura interna del cuestionario se realizó un análisis factorial confirmatorio (AFC). También se obtuvieron los índices de a de Cronbach y se compararon las puntuaciones de las escalas en relación con el género, el empleo de infusor de insulina, el grado de actividad física y la participación (sí/no) en grupos de apoyo. Los resultados indicaron
Corresponding author:

*Marcos Cupani

E-mail: marcoscupdagmail.com
Received for publication: 14-02-2018

Accepted for publication: 26-04-2018

Doi:10.24875/ALAD.18000328 
tory. The DSQOLS is a reliable and valid measure of specific health-related quality-of-life in people with DM1. It allows to distinguish between patients with different treatment regimens as well as to detect social inequalities. It can also be helpful to identify motivational deficits and to adapt strategies of individual treatments. (Rev ALAD. 2018;8:57-66)

Corresponding author: Marcos Cupani,

marcoscup@gmail.com

Key words: Diabetes. Quality of life. Confirmatory factor analysis. que el modelo ajustaba adecuadamente a los datos. La fiabilidad de las escalas fue satisfactoria. EI DSQOLS es una medida fiable y válida de CVRS específica de las personas con DM1. Permite distinguir entre pacientes con diferentes regímenes de tratamiento, así como también detectar desigualdades sociales. Puede ser útil también para identificar déficits motivacionales y adaptar estrategias de tratamiento individuales.

Palabras clave: Diabetes. Calidad de vida. Análisis factorial confirmatorio.

\section{INTRODUCTION}

The impact of a chronic disease has traditionally been measured in terms of morbidity and mortality. However, new research has begun to recognize the health-related quality-of-life (HRQL) as an important and measurable result of health interventions. In general, there are two types of evaluations: general and specific. General measures have been developed to evaluate people with various diseases and are useful for comparing different populations. However, researchers have suggested that they are less sensitive to changes in performance compared to specific measures ${ }^{1}$, which are designed to measure specific characteristics of a particular disease or population ${ }^{2}$. According to Jacobson ${ }^{3}$, the ideal evaluation of the quality of life incorporates both types of measures.

Diabetes mellitus (DM) impacts negatively on the quality of life of the patients that suffer from it. It is known that treatment adherence, complications from treatment, daily administration of insulin, economic costs, and some other related problems influence the physical, emotional, and social welfare of the patient. This has been shown in many studies ${ }^{4-8}$. The diabetes treatment main axes include nutritional recommendations, diabetes education, exercise, and self-control as well as pharmacotherapy, which require an effort to modify previously established habits as well as the predisposition to keep them. Hence, we can mention the complexity of treatment, even more so if we consider that adults are more reluctant to change $^{9}$. Most of the time, treatment success depends on these and other variables, which is why patient self-perception of these indicators must be included. This is what the quality of life scales achieve $^{10}$.

Assessments about the quality of life in diabetes patients showed positive effects on them, at physical, social, and psychological levels ${ }^{10}$. Therefore, identifying factors that have greater relevance when it comes to measuring the quality of life has been a relevant research goal. 
There are various scales that were made to measure different aspects related to type 1 diabetes. Among them, we can mention the diabetes attitude scale ${ }^{11}$, which consists of 50 questions and measures attitudes and motivations in diabetes. On the other hand, the diabetes treatment satisfaction questionnaire, developed by Bradley ${ }^{12}$, consists of 8 items that measure treatment satisfaction, metabolic control, and flexibility. The psychological well-being and treatment satisfaction scale ${ }^{13}$, which consists of 11 questions and assesses treatment satisfaction, can also be mentioned. The Ipswich diabetes self-management questionnaire ${ }^{14}$ has 41 questions that assess attitudes and their influence on self-management and metabolism. The diabetes educational profile ${ }^{15}$, has 110 items that examine the relationship between control/disease and psychological impact. On the other hand, the diabetes care profile ${ }^{16}$, consists of 243 questions that measure factors related to diabetes and its treatment. In addition, the diabetes quality of life scale, developed by the diabetes control and complications trial group, consists of 46 items that assess the quality of life subjective perception - impact, satisfaction, and social concerns related to diabetes. Finally, the patient satisfaction survey, made by the American Hospital Picker Association and the Picker Institute, performs a subjective assessment of the aspects that patients perceive as important ones.

The diabetes-specific quality-of-life scale (DSQOLS) is a scale designed to evaluate the main components of the quality of life (physical, emotional, and social burdens along daily treatment) specifically in patients with type 1 diabetes. This scale has proven to have suitable reliability and validity indexes. At the same time, it allows to distinguish between patients with different treatment and dietary regimes and to detect social inequalities.

\section{MATERIALS AND METHODS}

\section{Participants}

The sample was composed of 223 patients with type 1 diabetes of both sexes, 168 women (75.3\%) and 55 men (24.7\%), whose ages ranged between 18 and 71 years $($ mean $=35.77$; standard deviation $=12.2$ ) who participates voluntarily, consented and informed. Considering demographic characteristics, occupational, and educational levels reached, the sample can be classified into the following social classes: high (20.6\%), middle-high (12.1\%), typical middle (13\%), superior low (25.6\%), iñferior low (25.1\%), and marginal (3.6\%). Sample was recruited from January 2015 to August 2016.

\section{Instrument}

DSQOLS 64 items were specifically designed for people with DM1. Items are grouped to measure treatment goals (10 items); treatment satisfaction according to treatment goals (10 items); physical complaints (10 items); emotional burdens and worries (8 items); social problems (9 items); daily functions (work, leisure, and time requirements: 11 items), and diet restrictions (6 items). Participants must answer using a scale from 1 (completely important) to 6 (completely unimportant) for the treatment goals scale, a scale from 1 (very satisfied) to 6 (completely dissatisfied) for the treatment satisfaction, and a scale from 1 (perfectly) to 7 (not at all) for quality of dife related scales.

For DSQOLS adaptation a direct translation method was used, where the 64 scale items were translated from English into Spanish by three English language specialists. The three translations were compared, 
and linguistic adjustments were made. Then, a number of cognitive interviews were made to a DM1 patient sample. This qualitative method consists in assessing the clarity, intelligibility, fitness, and cultural importance of every item through personal interviews ${ }^{17}$. In this way, participants' mental processes were analyzed when answering the questionnaire and detecting difficulties, such as item wording or answer format. Interview record was performed through note-taking. Each interviewee was given a questionnaire. Each interviewee was asked to read each item and to mention what they understood and how they could describe in their own words the behavior signaled by the item. Consequently, items whose phrasing was little familiar for the population were reviewed and some expressions were changed toward a more everyday vocabulary. In the same way, considering that participants mentioned difficulties to understand the scales original questions, the 44 specific quality of life items were changed for a five-option answer scale ranging from 1 (I strongly agree with this description) to 5 (I strongly disagree with this description) for all 10 items of the goals scale; a five-option scale ranging from 1 (not important at all) to 5 (very important) for the treatment satisfaction 10 items; and a five-option scale ranging from 1 (very dissatisfied) to 5 (very satisfied) for scales related to quality of life. To obtain direct scale scoring, item scores were added and divided by the total number of items per scale. This way, DSQOLS score mean is found in a range from 1 to 5 , where number five stands for greater quality of life and fitness to treatment.

\section{Procedure}

Although a random selection was intended, the resulting selection was accidental. The administration was carried out online and was voluntary through the Lime Survey virtual platform. The questionnaire link was sent through email and several social networks, mainly Facebook. As regards administration formal aspects, participants were not given the possibility to save their answers and to complete the questionnaires later. Participants were not given the possibility to complete the survey more than once from the same IP address either, to avoid duplicate answers or more than one answer per person. The allotted time to complete the questionnaire was approximately $20 \mathrm{~min}$. Only those patients of 18 years of age or older who gave informed consent willing to take part in this research could take part.

\section{Data analysis}

A first analysis examined skewness (Sk) and kurtosis (Ks) of each item. As a criterion to assess Sk and Ks indexes, values between +1.00 and -1.00 were considered as excellent, and values below +2.00 and -2.00 were considered as adequate ${ }^{18}$. Furthermore, discrimination indexes of each subscale (item-total correlation) were obtained, where correlations that were not significant or low in relation to the total score $(<0.30)$ show that those items should be reviewed. A confirmatory factor analysis (CFA) was performed to evaluate the internal structure of the questionnaire using Mplus 6.12 program $^{19}$. To do this, the weighted least squares estimation method was used. This method is considered the most adequate when analyzing categorical data (for example, Likert scales) and it works appropriately if the sample size is $\geq 200^{20}$. To assess the fitness of the models, the comparative fit index (CFI), the Tucker-Lewis index (TLI), the root mean square error of approximation (RMSEA), and the weighted root mean residual (WRMR). Values between 0.90 and 0.95 or higher for CFI and TLI are considered a fit from acceptable to excellent. With RMSEA 
expected values are between 0.05 and 0.08 , and with WRMR values close to $1.00^{21}$. To study internal consistency, Cronbach's alpha coefficient was calculated and values higher than 0.70 were considered acceptable and values $>0.80$ were satisfacto$\mathrm{ry}^{22}$. Direct scores of each scale were calculated with the items summation which is defined a priori by the instrument and a concurrent validity study with the treatment goals scale and treatment satisfaction scale was conducted. The Pearson's $r$ correlation coefficient was used for this correlation analysis. Then, a study of validity evidence of groups comparing the mean scores in relation to participants' sex, whether insulin pump is used, whether the systematic physical activity is performed, and whether the subject takes part in support groups or social networks were carried out. This analysis was only performed for those patients diagnosed with type 1 diabetes. A t-test of differences between means was performed. Cohen's $d$ was used to estimate the size of the effect and for its interpretation small values $(\mathrm{d}=0.20)$, medium values $(\mathrm{d}=0.50)$, and large values $(\mathrm{d}=0.80)$ were considered. Later, to compare the average scores considering the socioeconomic level an analysis of variance (ANOVA) was used. To estimate the size of the effect, the partial eta squared coefficient (small values, $\eta^{2}=1 \%$; medium values, $\eta^{2}=10 \%$, and large values, $\eta^{2}=25 \%$ ) was used ${ }^{23}$.

\section{RESULTS}

\section{Analysis of items}

The goals scale item-total correlation values ranged between 0.05 and 0.43 ; the satisfaction values between 0.31 and 0.64 ; daily functions between 0.25 and 0.72 ; physical complaints between 0.46 and 0.70 ; social problems between 0.49 and 0.64; emotional burdens and concerns between 0.33 and 0.57; and diet restrictions between 0.28 and 0.64 . As regards the analysis of asymmetry, 50 of 64 items had values between +1 and -1 , considered by the literature as excellent, while 12 had values between +2 and -2 , which are also adequate. Only 2 items had high values of asymmetry. About the analysis of kurtosis, 40 items had values between +1 and $-1,16$ items were between +2 and -2 , and 4 items had inadequate values.

\section{Confirmatory factor analysis}

A CFA based on the original model consisting of five latent factors (physical complaints, emotional burdens and concerns, social problems, daily functions, and dietary restrictions) and on all 44 items of the scale as indicators were performed. The results showed that the model fits properly to the data (CFI 0.908, TLI 0.903, RMSEA 0.066, Cl 0.0610.07 , and WRMR 1.293). Standardized regression weights $(p \leq .05)$ in the daily functions factor ranged between 0.37 and 0.83 , diet restrictions ranged between 0.21 and 0.68 , physical complaints ranged between 0.52 and 0.87 , social problems ranged between 0.61 and 0.77 , and emotional burdens and concerns ranged between 0.26 and 0.77 . By removing Diet37 and Worries 36 items because their factor load was $<0.30$ and re-running the model of five factors and 42 indicators, the fit was slightly higher (CFI 0.926, TLI 0.921, RMSEA 0.062, Cl 0.057-0.067, and WRMR 1.199). Despite this slight gain in the fit of the model, it was decided to keep those 2 items. The study of internal consistency of each scale was carried out using the Cronbach's alpha coefficient, with these values: daily functions: $\alpha=0.83$, diet restrictions: $a$ $=0.71$, physical complaints: $\alpha=0.88$, social problems: $a=0.84$, and emotional burdens and concerns: $\alpha=0.75$ (Table 1). 
TABLE 1. Analysis of items and factor loads of all 44 quality-of-life items

\begin{tabular}{|c|c|c|c|c|c|}
\hline & \multicolumn{3}{|c|}{ Descriptive analysis } & \multicolumn{2}{|c|}{ Factor loadings $\infty$} \\
\hline & Item-Total & As & Ks & Beta & $\mathbf{R}^{2}$ \\
\hline Daily functions ${ }^{1}$ & 0.25 & 0.39 & -1.04 & 0.37 & 0.14 \\
\hline Daily functions ${ }^{11}$ & 0.64 & -0.03 & -1.04 & 0.70 & 0.49 \\
\hline Daily functions ${ }^{12}$ & 0.60 & -0.16 & -1.08 & 0.67 & 0.45 \\
\hline Daily functions ${ }^{13}$ & 0.50 & 0.34 & -0.89 & 0.61 & 0.37 \\
\hline Daily functions $s^{21}$ & 0.39 & 1.05 & 0.61 & 0.60 & 0.36 \\
\hline Daily functions ${ }^{23}$ & 0.61 & 0.33 & -0.85 & 0.77 & 0.60 \\
\hline Daily functions ${ }^{28}$ & 0.42 & 0.12 & -1.02 & 0.42 & 0.18 \\
\hline Daily functions ${ }^{29}$ & 0.72 & 0.72 & -0.35 & 0.82 & 0.67 \\
\hline Daily functions 35 & 0.65 & 0.68 & -0.36 & 0.83 & 0.69 \\
\hline Daily functions 39 & 0.45 & 0.18 & -1.12 & 0.47 & 0.22 \\
\hline $\operatorname{Diet}^{2}$ & 0.46 & -0.36 & -0.95 & 0.66 & 0.44 \\
\hline $\operatorname{Diet}^{15}$ & 0.28 & -0.29 & -0.98 & 0.57 & 0.33 \\
\hline Diet $^{20}$ & 0.59 & 0.63 & -0.30 & 0.68 & 0.46 \\
\hline $\operatorname{Diet}^{32}$ & 0.64 & 0.31 & -1.09 & 0.73 & 0.54 \\
\hline Diet $^{37}$ & 0.27 & -0.31 & -0.87 & $0.21 a$ & 0.04 \\
\hline Diet $^{41}$ & 0.45 & 0.53 & -0.51 & 0.67 & 0.44 \\
\hline Physical $^{3}$ & 0.59 & 0.58 & -0.74 & 0.65 & 0.42 \\
\hline Physical $^{10}$ & 0.70 & -0.27 & -0.91 & 0.82 & 0.68 \\
\hline Physical $^{14}$ & 0.46 & 0.30 & -0.99 & 0.52 & 0.27 \\
\hline Physical ${ }^{17}$ & 0.51 & 0.28 & -0.97 & 0.57 & 0.32 \\
\hline Physical $^{19}$ & 0.70 & 0.50 & -0.84 & 0.78 & 0.60 \\
\hline Physical $^{22}$ & 0.70 & 0.41 & -0.83 & 0.74 & 0.55 \\
\hline Physical $^{26}$ & 0.56 & 0.42 & -0.95 & 0.63 & 0.40 \\
\hline Physical $^{27}$ & 0.54 & 0.03 & -1.18 & 0.63 & 0.39 \\
\hline Physical ${ }^{30}$ & 0.65 & 1.02 & -0.05 & 0.87 & 0.76 \\
\hline Physical ${ }^{31}$ & 0.52 & 0.37 & -0.89 & 0.63 & 0.40 \\
\hline Physical 43 & 0.66 & 0.65 & -0.40 & 0.78 & 0.61 \\
\hline Social ${ }^{4}$ & 0.49 & 0.78 & -0.20 & 0.61 & 0.38 \\
\hline Social $^{6}$ & 0.52 & 0.84 & -0.25 & 0.68 & 0.47 \\
\hline Social9 & 0.61 & 0.39 & -0.98 & 0.68 & 0.46 \\
\hline Social|18 & 0.57 & -0.30 & -1.00 & 0.68 & 0.46 \\
\hline Social ${ }^{24}$ & 0.54 & 1.17 & 0.89 & 0.71 & 0.51 \\
\hline Social|34 & 0.54 & 0.30 & -0.98 & 0.61 & 0.37 \\
\hline Social ${ }^{38}$ & 0.64 & 0.93 & 0.19 & 0.77 & 0.60 \\
\hline
\end{tabular}


TABLE 1. Analysis of items and factor loads of all 44 quality-of-life items (continuation)

\begin{tabular}{|c|c|c|c|c|c|}
\hline & \multicolumn{3}{|c|}{ Descriptive analysis } & \multicolumn{2}{|c|}{ Factor loadings $\infty$} \\
\hline & Item-Total & As & Ks & Beta & $\mathbf{R}^{2}$ \\
\hline Social ${ }^{42}$ & 0.59 & 0.68 & -0.55 & 0.76 & 0.58 \\
\hline Social ${ }^{44}$ & 0.54 & 1.75 & 3.52 & 0.72 & 0.51 \\
\hline Worries 5 & 0.57 & -0.26 & -1.19 & 0.55 & 0.30 \\
\hline Worries ${ }^{7}$ & 0.49 & 0.10 & -0.89 & 0.77 & 0.59 \\
\hline Worries ${ }^{8}$ & 0.50 & -1.35 & 1.56 & 0.50 & 0.25 \\
\hline Worries $^{16}$ & 0.40 & 0.36 & -0.78 & 0.69 & 0.48 \\
\hline Worries 25 & 0.37 & 0.85 & -0.34 & 0.74 & 0.55 \\
\hline Worries 33 & 0.48 & -1.14 & 1.40 & 0.41 & 0.17 \\
\hline Worries 36 & 0.33 & -1.08 & 1.16 & $0.26^{a}$ & 0.07 \\
\hline Worries ${ }^{40}$ & 0.40 & -0.36 & -0.90 & 0.55 & 0.31 \\
\hline
\end{tabular}

altem that is removed and improves the model fit.

\section{Evidence of validity}

\section{CORRELATION}

A moderate and positive correlation between satisfaction and daily functions (0.47), diet restrictions (0.39), physical complaints (0.51), social problems (0.34), and emotional burdens and concerns (0.49) was seen. A positive correlation was also seen among the five factors of quality of life. There was a significant relationship with the treatment goals but with a small size effect (-0.13) (Table 2).

\section{DIFFERENCE OF MEAN AMONG CONTRASTED GROUPS}

It was seen that women had higher scores than men and these were statistically significant for treatment goals $(\mathrm{d}=0.35)$. On the other hand, men scored higher than women. The score was statistically significant for satisfaction $(d=0.32)$, diet restrictions $(d=0.62)$, physical complaints $(d=0.49)$, and emotional burdens and concerns $(d=0.58)$. On the other hand, that patients using insulin pump had higher scores than those not using it, and these were statistically significant for dietary restrictions $(d=0.46)$. About patients performing a systematic physical activity, it was seen that they scored higher for treatment goals $(d=0.34)$, satisfaction $(d=0.55)$, daily functions $(d=0.29)$, physical complaints $(d=0.44)$, and emotional burdens and concerns $(d=0.32)$ in comparison with those notperforming physical activity. Finally, it was seen that patients who take part in support groups or social networks scored higher for dietary restrictions $(d=0.34)$ in comparison with patients who do not perform this activity.

\section{COMPARISON OF GROUPS ACCORDING TO SOCIOECONOMIC LEVEL}

Socioeconomic status (SES) was included as an independent variable or factor in ANOVA and the scores on the scales were included as a dependent variable. The SES variable showed a significant influence on the direct score for the physical 
TABLE 2. Mean and deviation of the scales and correlation analysis

\begin{tabular}{|c|c|c|c|c|c|c|c|c|c|c|c|}
\hline & & M & SD & 1 & 2 & 3 & 4 & 5 & 6 & $\stackrel{\infty}{-\infty}$ & 7 \\
\hline 1 & Treatment goals & 4.03 & 0.41 & 1.00 & -0.01 & -0.11 & -0.14 & -0.09 & -0.09 & 9 & $-0.14^{*}$ \\
\hline 2 & Satisfaction & 3.12 & 0.78 & & 1.00 & 0.50 & 0.42 & 0.53 & 0.35 & & 0.54 \\
\hline 3 & Everyday functions & 3.39 & 0.76 & & & 1.00 & 0.60 & 0.78 & 0.71 & & 0.68 \\
\hline 4 & Dietary restrictions & 3.12 & 0.75 & & & & 1.00 & 0.55 & 0.50 & (c) & 0.56 \\
\hline 5 & Physical complaints & 3.45 & 0.82 & & & & & 1.00 & 0.68 & & 0.70 \\
\hline 6 & Social problems & 3.76 & 0.73 & & & & & & 1.00 & - & 0.64 \\
\hline 7 & $\begin{array}{l}\text { Emotional burdens and } \\
\text { concerns }\end{array}$ & 2.74 & 0.68 & & & & & & & $\frac{\overline{0}}{\frac{2}{3}}$ & 1.00 \\
\hline
\end{tabular}

complaints scale $\left(F[5,217]=3.369 ; p=0.006 ; \eta^{2}=\right.$ 0.07). Post hoc analyses with Tukey's HSD test ( $p<$ 0.05 ) showed that patients of marginal and inferior lower classes scored lower on this scale in comparison to upper-class patients.

\section{DISCUSSION}

The purpose of this study was to adapt the DSQOLS ${ }^{10}$ into Spanish, specifically for the population in Argentine having type 1 diabetes. In general, the psychometric results of the scale are satisfactory. Indeed, studies of the CFA allowed to corroborate that the original five-factor model (daily functions, diet restrictions, physical complaints, social problems, and emotional burdens and concerns) is a workable model to measure the quality of life in patients with diabetes.

On the other hand, the internal consistency analysis for each scale showed values that are adequate for these. The five subscales showed scores higher than 0.70. In addition, a bivariate correlation analysis was carried out where a moderate and positive correlation between the five factors and treatment satisfaction was seen. These results coincide with those reported by other studies where this scale was used ${ }^{10,24}$.
The group comparison studies showed that women aim at higher treatment goals than men, while the latter show higher treatment satisfaction, better acceptance of diet restrictions, and fewer physical complaints and emotional burdens, besides concerns about type 1 diabetes. These results are consistent with the previous studies ${ }^{25,26}$, who claim that women with diabetes show a more negative impact than men on the HRQL level. As regards the socioeconomic level it could be seen that patients of marginal and inferior lower classes showed less quality of life with respect to diet in comparison to patients belonging to a high class.

On the other hand, patients who perform physical activity systematically showed higher treatment goals, higher treatment satisfaction, and better quality of life in relation to daily functions, physical complaints, and emotional burdens and concerns. It can also be seen that patients who take part in support groups or social networks showed better quality of life in relation to diet restrictions. With respect to this point, Bloom ${ }^{27}$ stated that social support can influence the quality of life in two ways, either directly, by fostering motivation to engage in adaptive behaviors, or indirectly, by causing higher adherence to therapeutic recommendations prescribed by the physician. It is for this reason that 
social support networks are a mitigating factor in the impact of stress-inducing circumstances ${ }^{28}$.

Regarding the limitations of this study, it must be considered, in the first place, that the sample was composed of a higher percentage of women, which generates a disproportion and would cause results to be biased by sex. Second, another limitation has to do with the influence of the participants' ages, which is of wide-range and no analysis has been done to see how the perception of quality of life in younger individuals can be affected in comparison to adults. Third, it should be considered that only reliability was evaluated in its internal consistency dimension, so it is recommended for later works perform a test-retest study to generate evidence of reliability in the temporal stability dimension. However, no evidence of discriminant validity was also evaluated, although there were studies that carried out the adaptation of this scale to different populations and found meaningful results on this dimen$\operatorname{sion}^{10,24}$. Another of the limitations that we can point out in this work is the fact that the analyses carried out were from the Classical Test Theory. Item Response Theory gains more popularity as it can offer invariant measures, regardless of the instruments used and the individual's evaluated ${ }^{29}$. This is because with these models one could obtain more representative measures about the different variables that the DSQOLS has in its structure. On the other hand, it was not possible to obtain direct objective indexes of each patient, which would allow to make estimates about the cases that make significant changes in the different dimensions of the questionnaire, which constitutes an adequate tool so that the professional can make reliable clinical decisions, with respect to individual subjects ${ }^{30}$.

In general, this work has reported results that are more than encouraging in the adaptation of this scale to a clinical population in the context of our population. The growing need for reliable and valid measures of the different dimensions that lead to research and evaluation of type-1 diabetes patient quality of life, causes this work to be a substantial contribution to study of the psychosocial, sociodemographic, and psychological variables that are involved in the quality of life of patients suffering this disease. The use of DSQOLS for the evaluation of treatment individual goals according to patient definition can be useful to identify motivational deficits and to adapt individual treatment strategies. DSQOLS captures the impact of DM1 modern management aspects (for example, carbohydrate counting and flexible insulin dose adjustment) which are now routine in many parts of the world.

\section{REFERENCES}

1. Guyatt GH, Bombardier C, Tugwell PX. Measuring disease-specific quality of life in clinical trials. CMAJ. 1986;134:889-95.

2. Robles-García R, Cortázar J, Sánchez-Sosa JJ, Páez-Agrar F, Nicolini-Sánchez H. Evaluación de la calidad de vida en diabetes mellitus tipo II: propiedades psicométricas de la versión en español del DQOL. Psicothema. 2003;15:247-52.

3. Jacobson AM, de Groot M, Samson JA. The evaluation of two measures of quality of life in patients with Type I and Type II diabetes. Diabetes Care. 1994;17:267-74.

4. Chlebowy DO, Garvin BJ. Social support, self-efficacy, and outcome expectations: impact on self-care behaviors and glycemic control in Caucasian and African American adults with Type 2 diabetes. Diabetes Educ. 2006;32:777-86.

5. DiMatteo MR. Social support and patient adherence to medical treatment: a meta-analysis. Health Psychol. 2004;23:207-18.

6. Ortiz SM. Factores psicológicos y sociales asociados a la adherencia al tratamiento en adolescentes diabéticos tipo 1. Psykhe. 2004;13:21-31.

7. Paddison CA, Alpass FM, Stephens CV. Psychological factors account for variation in metabolic control and perceived quality of life among people with Type 2 diabetes in New Zealand. Int J Behav Med. 2008; 15:180-6.

8. Sacco WP, Yanover T. Diabetes and depression: the role of social support and medical symptoms. J Behav Med. 2006;29:523-31.

9. Papalia DE, Olds SW, Feldman RD, Salinas ME. Desarrollo Humano. México, DF: McGraw-Hill; 2005.

10. Bott U, Mühlhauser I, Overmann H, Berger M. Validation of a diabetes-specific quality-of-life scale for patients with Type 1 diabetes. Diabetes Care. 1998;21:757-69.

11. Anderson RM, Donnelly MB, Dedrick RF. Measuring the attitudes of patients towards diabetes and its treatment. Patient Educ Couns. 1990;16:231-45.

12. Bradley C. Diabetes Treatment Satisfaction Questionnaire (DTSQ). Handbook of Psychology and Diabetes. Chur, Switzerland. Reading: Harwood Academic Publisher; 1994. p. 111-32. 
13. Bradley C, Lewis KS. Measures of psychological well-being and treatment satisfaction developed from the responses of people with tablet-treated diabetes. Diabet Med. 1990;7:445-51.

14. Day JL, Bodmer CW, Dunn OM. Development of a questionnaire identifying factors responsible for successful self-management of insulin-treated diabetes. Diabet Med. 1996;13:564-73.

15. Davis WK, Hess GE, Harrison RV, Hiss RG. Psychosocial adjustment to and control of diabetes mellitus: differences by disease type and treatment. Health Psychol. 1987;6:1-4.

16. Fitzgerald JT, Davis WK, Connell CM, et al. Development and validation of the diabetes care profile. Eval Health Prof. 1996;19:208-30.

17. Paul CB, Gordon BW. Research synthesis: the practice of cognitive interviewing. Public Opin Quarterly. 2007;71:287-311.

18. George D, Mallery P. SPSS for Windows Step by Step: a Simple Guide and Reference, 11.0 Update. Boston: Allyn \& Bacon; 2003.

19. Muthén LK, Muthén BO. Mplus User's Guide. $6^{\text {th }}$ ed. Los Angeles, CA: Muthén \& Muthén; 2011.

20. Flora DB, Curran PJ. An empirical evaluation of alternative methods of estimation for confirmatory factor analysis with ordinal data. Psychol Methods. 2004;9:466-91.

21. Yu CY, Muthén B. Evaluation of Model Fit Indices for Latent Variable Models with Categorical and Continuous Outcomes. New Orleans, LA: Annual Meeting of the American Educational Research Association; 2002.
22. Hogan T. Pruebas Psicológicas. Una Introducción Práctica. México, D.F.: El Manual Moderno; 2004.

23. Cohen J. Statistical Power Analysis for the Behavioral Sciences. New York: Routledge Academic; 1988.

24. Cooke D, O'Hara MC, Beinart N, et al. Linguistic and psychometric validation of the diabetes-specific quality-of-life scale in U.K. English for adults with type 1 diabetes. Diabetes Care. 2013;36:1117-25.

25. Eiser C, Flynn M, Green E, et al. Quality of life in young adults with Type 1 diabetes in relation to demographic and disease variables. Diabet Med. 1992;9:375-8.

26. Lloyd CE, Orchard TJ. Physical and psychological well-being in adults with Type 1 diabetes. Diabetes Res Clin Pract. 1999;44:9-19.

27. Bloom JR. The relationship of social support and health. Soc Sci Med. 1990;30:635-7.

28. Baqutayan S. Stress and social support. Indian J Psychol Med. 2011; 33:29-34.

29. Hambleton RK, Swaminathan H. Item Response Theory: principles and Applications. Boston, MA: Kluwer-Nijhoffl; 1985.

30. Montero M, Iraurgi I, Matellanes B, Montero JM. Uso del índice de cambio fiable en la evaluación de la efectividad de intervenciones clínicas: aplicación en un programa formativo en asma. Aten Primaria. 2015;47:644-52. 